\title{
Religious Motivation, Nepotism and Conflict Management in Jordan
}

Peer reviewed version forthcoming in the International Journal of Conflict Management

DOI: 10.1108/IJCMA-02-2017-0015

\section{Andrea Caputo}

Reader in Entrepreneurship

Lincoln International Business School

University of Lincoln

Lincoln, UK

acaputo@lincoln.ac.uk

\begin{abstract}
Purpose - The purpose of this research paper is to investigate the role of individual and cultural differences, specifically religious motivation and attitudes toward nepotism, in the selection of conflict management styles (obliging, avoiding, forcing, integrating, and compromising), in the Middle-Eastern context.

Design/methodology/approach - The research surveyed a sample of 588 individuals (both Muslims and Christians), representative of the Jordanian population. Data were analyzed through multiple ANOVAs and Multiple Regressions.

Findings - Results suggest that both religious motivation and attitude toward nepotism affect the choice of conflict management styles, while demographic variables, such as age and gender, do not seem to have an effect.

Originality/value - This paper constitutes one of the first attempts to investigate the conflict management style preferences of a Middle-Eastern society and the role of two important cultural variables, namely religious motivation and attitudes toward nepotism, which have not been previously investigated by conflict management research.
\end{abstract}

Keywords: Conflict Management Styles, Nepotism, Religious Motivation, Middle East, Individual Differences

\section{Acknowledgments}

The author thanks the Editor and the anonymous reviewers for the helpful and valuable comments. A special thanks goes to Lamees Al Maita, Nadeen Fakhoury, and Sinan Jarrad for helping in the data collection as part of their graduation project at Princess Sumaya University for Technology in Amman, Jordan. 


\section{Introduction}

Jordan is a culturally and religiously diverse country, with a strategic position in the midst of turmoil. Neighboring Iraq, Israel, Palestine, Syria and Saudi Arabia, Jordan was able to create many relations and play different strategic roles through its eventful years as an independent country. Those dynamics highly influenced both the society and its demographics. Jordan has an estimated population of $7,930,491$, which is highly comprised of refugees. Specifically, 25.9\% of its population comprises Palestinian refugees (UNRWA, 2013), 17.8\% consists of Syrian refugees, and $0.294 \%$ is comprised of Iraqi refugees (UNHCR, 2013). The remainder of the population is made up by Jordanian citizens and non-refugee foreigners living in the Country. This eclectic population has grown throughout the years as a result of wars and disputes dating back to the Arab-Israeli war in 1948. Arabs constitute about $98 \%$ of the population, while Circassians and Armenians both constitute about $1 \%$ each, respectively. In a climate of multiculturalism and respect Sunni Muslims comprise about $92 \%$ of the population, while Christians comprise about $6 \%$ of the population; the remaining $2 \%$ is made up of Shia Muslims and Druze (Central Intelligence Agency, 2014). The Jordanian society is collectivist, paternalistic, patriarchal, and tribal. Religion plays an important role in its governance, with the society exhibiting a predominance of the Muslim religion. While the way Islam is practiced may vary from country to country in the region, the Islamic religion has an important influence over societal norms, political systems and is considered to be a way of life (Caputo et al., 2016). Indeed, the Jordanian legal system is also based on the Sharia (religious) law.

Jordan is a service-based economy home to a number of multinational organizations, NGOs and International Institutions (e.g. UN agencies). At the same time, Jordan is known for being a country based on tribal affiliations: social status, political life and business life are strongly affected by a system of "soft influences" in which tribal and religious affinity are intertwined (Rowland 2009). In the words of Rowland (2009, p. 6): "the social system in Jordan is still largely based on tribalism and kinship relations, particularly in rural areas. This social structure is less prominent in urban areas, as the Palestinian-Jordanians that are concentrated there are considered to be less tribal. This system is traditionally patriarchal, though remarkably egalitarian when it comes to economic status, and inspires a fierce loyalty to the tribe from all members. In Jordan more so than some other countries in the region where ethnic and religious conflicts have dominated politics, tribalism plays an extremely significant role in the political process". As a consequence, it is quite accepted that "everything, no matter how simple it is, requires a wasta in Jordan" (El-Said and McDonald, 2001, p. 77). The word wasta is the core concept related to tribalism: favoritism based on family and tribal relations. The same mechanisms can be found across other Arab countries, where wasta is referred to as ma'arifa (“who you know") or piston (“pulling strings") (Yahiaoui and Zoubir, 2006). 
This study, through a survey of 588 individuals living in Jordan, is a comparative analysis of conflict style preferences in Jordan, as a case study for the Middle East, which is especially concerned with the differences between the major religious motivations and nepotistic attitudes within the country. The history of the Middle East has been heavily influenced by both religious and ethnic conflict, yet little research has led to a greater understanding of the effects such a history has had on the present environment. Conflict management in the Middle East has been extensively researched in political science and in the area of global geopolitics. However, it is still under-researched in the organizational behavior field.

The paper has the following structure. The next section presents a literature review to build the theoretical background on conflict management and its relationships with religious motivation and nepotism. Then the methods are presented and results discussed. Finally, the paper offers both theoretical and practical implications.

\section{Theoretical background}

\subsection{Conflict Management Styles}

Conflict is a widely researched and defined topic. Tjosvold (2006) defined conflict as arising "from opposing interests involving scarce resources and goal divergence and frustration" (p. 88). Conflict can have negative results (dysfunctional conflict) or positive results (functional conflict), depending on the situation and on the individuals involved (De Dreu, 2008). Managing conflict effectively either in the working environment or in day-by-day life is one of the challenges that everyone faces on a regular basis, regardless of their position. As such, conflict management is an understanding of conflict as a whole, its triggers, the conflict cycle, and the conflict management styles and behaviors involved (Ayoko et al., 2002). Despite individual characteristics and differences in contexts, i.e. the fact that every configuration of situation and actors is different, individuals tend to adopt certain patterns, or styles, when managing conflict situations (Euwema et al., 2003; Oetzel, 1998; Ting-Toomey et al., 2001). A conflict style, or behavior, is a general pattern of actions and behaviors an individual tends to adopt in order to handle situations of conflict (Brew and Cairns, 2004; Van de Vliert and Kabanoff, 1990).

In other words, the conflict management style adopted is the result of the decisions we made when aiming to manage the conflict. Hitherto, the main model used in categorizing conflict management behaviors is the dual concern model (Blake and Mouton, 1964; Rubin et al., 1994). This framework differentiates the styles of handling conflict into two distinct dimensions: concern for self and concern for others. The concept of concern for self explains the degree to which a person tries to fulfill and satisfy his or her own goals. Combining these two dimensions is represented in the five different styles or behaviors of handling conflict (e.g., Rahim, 1983; Thomas and Kilmann, 1978): dominating (also referred as competing or 
contending), obliging (also referred as yielding or accommodating), integrating (also referred as problem-solving or collaborating), avoiding (or inaction), and compromising.

The dominating behavior involves high concern for self and low concern for the others; each party tries to pursue its own interests. Such style follows a win-lose approach where high levels of competition are found. There is no cooperation between parties, and the main aim is to win at any cost to satisfy personal concern, regardless of the concerns of others. The obliging style refers to "giving in to the opponent" (Euwema et al., 2003), and manifests when there is low concern for self and high concern for others. Avoiding involves low concern for self and low concern for others, and it is characterized by avoiding confrontation on the conflict issue with the other party. The integrating style takes place when there is an attempt to integrate the interests of the parties involved to reach a joint solution. Individuals who pursue this style show high concern for self and high concern for others. As a result, cooperation and collaboration is needed to reach acceptable solutions that will satisfy both parties. Finally, the compromising style represents a moderate effort to pursue one's personal interests and a moderate effort in helping the other party to also achieve his or her outcomes; the compromising style therefore refers to "settling through mutual concessions" (Euwema et al., 2003). That is, both parties give up something to obtain an acceptable decision.

This five part taxonomy derived from the dual concern model has been widely criticized due to concerns over its comprehensiveness (Conrad, 1991). For example, Van de Vliert and his colleagues (1995) pointed out how in reality people do not engage in single and separated conflict behaviors, rather they deploy behaviors that encompass a mix of the characteristics from problem solving to competing. Van de Vliert et al. presented a model of seven components of what they called "conglomerated" conflict behaviors. Although promising, the complexity behind this framework prevented a broad usage of it in conflict research (Euwema and Van Emmerik, 2007). Other scholars have tried to improve the dual concern model, by adding or integrating new styles (Leung and Kim, 2007; Ting-Toomey et al., 2001). However, a new and superior dominant framework is yet to emerge (Ayoko and Konrad, 2012). Therefore, for the purposes of this study and to allow for comparison, a refined instrument based on the dual concern model and its five conflict management styles was utilized (Oetzel, 1998). As the study is investigating conflict management styles in Jordan, which is a multi-cultural and multireligious environment, Oetzel's instrument is the most appropriate for the purposes of the present analysis, as it has been developed to take into consideration cultural diversity and it has been already used in research in similar contexts (e.g., Croucher et al., 2011). 


\subsection{Conflict Management Styles and Cultural Background}

Among the many theories to explain how conflict emerges and is managed across different cultures, researchers in the field usually employ three related theories to explain such phenomena: the similarity and attraction paradigm (Byrne, 1971), social categorization theory (Billig and Tajfel, 1973; Turner et al., 1987) and social identity theory (henceforth SIT, Hogg and Abrams, 1988; Tajfel, 1981). The similarity attraction paradigm (Byrne, 1971) predicts that similarities between attributes (e.g. attitudes, values) increase the tendency for interpersonal attraction and liking such that individuals with similar backgrounds may share common values and may find their interactions easier and more reinforcing than those with different values. Thus, the operation of similarity attraction paradigm may lead to difficult communication and interaction processes between different cultures (Harrison et al., 1998). Furthermore, Turner et al. (1987) described self-categorization theory as the process by which people define their selfconcept in terms of their membership of various social groups. Markus and Cross (1990) also suggest that self-categorization may be context dependent, because different aspects of a person's self-concept may become salient in response to the characteristics of others that are also present in a given environment or context. Similarly, the proponents of SIT (Hogg and Abrams, 1988; Tajfel, 1981) suggest that group members establish a positive social identity and confirm affiliation by showing favoritism to members of their own social category (Billig and Tajfel, 1973). Affiliation and favoritism to members sharing similar socio-cultural characteristics often result in biases, prejudices, and stereotypes.

Such mechanisms impact both the antecedents of conflict as well as its management (Ayoko and Härtel, 2003). For example, studies suggest how conflict management styles are learned during socialization processes in a group or a culture (Ting-toomey and Kurogi, 1998). In building their identities, individuals are influenced by learned behaviors which are activated through socialization and influenced by the cultural context in which the group is embedded (Hogg and Abrams, 1988; Tajfel, 1981). Indeed, conflict management styles differ across different cultural backgrounds, which has fueled research on viewing conflict as a cultural behavior (Kaushal and Kwantes, 2006; Triandis, 2000). Accordingly, differences in conflict management styles are explained based on cultural differences and group identity, rather than individual differences. High versus low-context scheme of cultural variability (Hall, 1976) has also been used to explain the reason behind the fact that different conflict management styles are adopted by individuals in different cultures (Ting-Toomey, 1985). In high-context cultures, the instrumental issue of a message is intertwined with the individual in whom the issue itself originated, while in low-context cultures a message and its sender are not necessarily intertwined (Hall, 1976). 
Similarly, differences in cultural orientations can explain diverse conflict behaviors among different cultures. Hofstede (1994) showed how people coming from different cultures look at events in different ways, which impacts on their perceptions. Cultural orientations (i.e. small vs. large power distance, individualism vs. collectivism, masculinity vs. femininity, weak vs. strong uncertainty avoidance, and long vs. short term orientation) are particularly likely to affect individuals' behavior in multicultural contexts. In this regard, the same event or behavior can be seen in a diametrically opposite way from two coworkers coming from a collectivistic and an individualistic culture. People from western countries, such as Americans and Australians, are generally assumed to be individualistic - emphasizing their individual identity over a broader group identity -, while people from eastern, often developing, countries, such as Africans, Asians and South Americans, are assumed to be collectivistic, collaborating and following social norms rather than focusing on their own needs (Cai and Fink, 2002; Oetzel et al., 2006). Studies comparing conflict management in individuals from different cultures have shown that individuals from high-context, collectivistic cultures tend to prefer styles that are more characterized by avoidance and accommodation than those of people from individualistic cultures (Adair et al., 2001; Chua and Gudykunst, 1987; Zhang, 2007). Accordingly, people from predominantly Muslim countries (e.g. Saudi Arabia, Indonesia, Jordan, India, Turkey and Pakistan) are assumed to be collectivistic (Croucher et al., 2011; Oetzel et al., 2006). Indeed, values tend also to vary by national culture, for example, eastern nations are more likely to endorse collectivism, while western nations are more likely to endorse individualism. In this regard, it is expected that cultural orientations have implications for conflict management styles (Morris and $\mathrm{Fu}, 2001$ ). Indeed, culture will more likely affect not only the conflict cycle itself but also the individual perceptions of the conflict and its triggers (Ayoko et al., 2003). Differences in culture may also impact the (mis)interpretations and the associated emotions (Ayoko and Konrad, 2012; Kumar, 2004) that may impact the evolution of the conflict processes and conflict management behaviors during conflict (Kaushal and Kwantes, 2006).

The concern for the "self" and for the "other" (groups) represents the two key aspects in the interpretation of cultural differences and the key concerns categorizing the five conflict management styles. The focus is on whose needs are generally emphasized by individuals in conflict situations. Most of the existing studies on culture and conflict explore comparisons between two or more different cultures, usually categorized as high- versus low-context and individualistic versus collectivistic cultures (Gelfand et al., 2002; Holt and DeVore, 2005; Morris and Fu, 2001; e.g. Sadri, 2013). This body of research shows a consistent relationship between one's culture and its respective and related conflict management styles. Nevertheless, the focus of the present study is not to compare differences, but rather to investigate how specific cultural facets act in relation to the chosen conflict management style. In doing so, the study aims to contribute to the understanding of the antecedent dynamics of the relationships 
between cultural differences and conflict management styles. Accordingly, using the same interpretations of "self" and "other", the attention is on two facets of the Middle Eastern culture: religious motivation and attitude toward nepotism, which are further explained in the following sections.

RQ1. What is the overall conflict management style preference in Jordan?

\subsection{Conflict Management Styles and Religious Motivation}

Jordan and other countries in the Middle East are generally understood to be highcontext, collectivistic countries (Oetzel et al., 2006). However, in addition to the classical cultural variables that are traditionally analyzed in cross-cultural studies, religion has also been found to play a role in influencing conflict styles (Croucher et al., 2011). The role of religion is particularly important in the Middle East, where sociopolitical changes have increased the importance of religious identity over and above national identity (Srour et al., 2013). For example, Polkinghorn and Byrne (2001) found significant differences in conflict styles based on the religious identity of participants from societies affected by conflict, namely South Africa, Bosnia-Herzegovina, Israel and Northern Ireland. Yet, most of those studies, as per the studies analyzing cultural differences, refer to comparisons between different religions (e.g., Croucher, 2011, 2013; Croucher et al., 2011; Polkinghorn and Byrne, 2001; Srour et al., 2013). For example, Croucher and colleagues (2011) investigated the conflict style preferences in India among Muslims and Hindus. In their study, they found that conflict style preferences differ between the two groups, with Hindus preferring integrating and dominating styles, whilst Muslims prefer integrating and compromising styles. These results were lately confirmed in another study, which found Hindus to be more prone toward dominating conflict situations, while Muslims tended to either avoid conflict or prefer integrating styles (Croucher, 2013). Similar results were also found when analyzing the conflict management styles of Muslims and Christians in Western Europe (Croucher, 2011), confirming the importance of the role of religious identity in explaining the choice of conflict management styles.

Within Jordan, the dominant religion is Sunni Islam, while Christians and other faiths constitute minorities. As is the same in many other predominantly Muslim countries, in Jordan freedom of religion is not only guaranteed but respected and preserved. Contradictory to the stereotypical view of all Arabs being Muslim which has been portrayed by western media in the last fifteen years, most of the countries in the Middle East respect diversity. Indeed, it is quite common to see a Church built in front of a Mosque. Nevertheless, religion plays a major role in social life in many of the Arab countries. However, there are many similarities between Islam and Christianity (Wilson and Power, 2004); for example, both religions believe in the one, true deity who sent messengers to guide human beings to salvation (Martin, 1998). These 
similarities result in similar social norms and behaviors across groups belonging to different faiths. For these reasons, in this study it was decided not to differentiate between different religions, rather the aim is to focus on how the interpretation and status of being a religious person influence conflict management styles.

Given the aforementioned dynamics predicted by Social Identity Theory (Hogg and Abrams, 1988; Tajfel, 1981) and based on personal knowledge of the context, it is argued that more than an affinity to a certain religion, people are characterized by the religious behaviors that they display. In social settings, respect and acceptance by the group is mostly gained by the extrinsic show of religious behavior; namely being known to practice a religion or participate in group praying and religious conversation in society is more of a determinant for acceptance into a group than the affinity to a certain religion. For example, in a university it is expected that academics participate in daily group prayers with colleagues if they are Muslim, while if they are of a different faith it is socially expected and assumed that the observance of one's own religion is maintained; it is rather frequent to be engaged in religious conversations in the workplace as in other social contexts, a characteristic of society that is different from western societies, where the practice of religion is considered to be a private matter. In this vein, some studies have investigated the role of religiosity, or the extent to which an individual believes in a higher power, has in affecting conflict styles. Among those, Wilson and Power (2004) compared Australian Christians and Muslims, distinguishing between practicing and non-practicing individuals within each group. Their findings showed that individuals with low religiosity tended to be more collaborative, while Muslims with high religiosity preferred the compromising style. For these reasons, and following recent calls for future research to deepen our understanding of how individual religiousness affects conflict management styles, this study focuses on investigating the religious motivation of an individual, rather than its religious identity.

Religious motivation can be defined as a measurement of how an individual approaches his or her religion; it is regarded as the drive behind each individual's perspective on religion. Accordingly, an individual can be classified as having either intrinsic or extrinsic religious motivation. An intrinsically motivated individual views religion as an end in itself (Neyrinck et al., 2010). He or she thrives by their religion and considers it to be a major motivating factor in life (Allport and Ross, 1967). An intrinsically motivated individual will go to a Mosque or Church because of his or her beliefs, realizing the importance of praying to his or her religion and recognizing it as a good deed. Conversely, an extrinsically motivated individual views religion as a method of acquiring personal gains such as security, sociability, status, selfjustification, and business contacts (Worthington Jr et al., 1996). He or she will "use religion for their own ends" (Allport and Ross, 1967, p. 434). An extrinsically motivated individual will engage in religious behaviors to maintain social contacts, to create a preferred image in society, 
or even for personal comfort. There have been studies in the past relating religious motivation to personality traits; intrinsic religiousness has been associated with agreeableness and conscientiousness (Saroglou, 2002), as well as with more integrated social behavior, less insecurity, and less anxiety (Baker and Gorsuch, 1982). In contrast, extrinsic religiousness has been associated with neuroticism (Saroglou, 2002), as well as with less integrated social behavior, more insecurity, and more anxiety (Baker and Gorsuch, 1982). Despite the lack of studies investigating the role of religious motivation in conflict management, it could be argued that the more religious an individual is, the more a focus might be placed on dealing with the issues as soon as possible, as clearing the air would be the 'right' thing to do (Kaushal and Kwantes, 2006). A belief in spirituality, rooted in a 'do good for others' approach, could be associated with the dimensions of intrinsic religious motivation, and as such might result in conflict management styles which are more prone toward integrating or obliging. Indeed, Kaushal and Kwantes (2006) found spirituality to be negatively related to the avoiding style of conflict management. Given the novelty of the present paper and lack of previous research on the subject, the following broad research question is posed.

\section{RQ2. Is intrinsic religious motivation a predictor of conflict management styles?}

\subsection{Conflict Management Styles and Nepotism}

Nepotism may be defined as a form of favoritism shown to relatives, as by giving them positions because of their relationship rather than their merit (e.g., Ford and McLaughlin, 1985). Different research perspectives in the field of organizational behavior and political science have contributed to further define nepotism. Different perspectives are identified, such as, for example, the employment of a family member by the owner or manager of a business, the employment of a spouse of an existing employee, or in a political setting, putting one's family members into political positions of favor, and finally the employment of an individual associated with an existing employee, other than the owner of the organization (Arasli et al., 2006). In general, nepotism is associated with favoring someone based on a common affinity to a specified group that is shared with the decision maker rather than based on individual skills and expertise. Accordingly, nepotism can be identified as a form of conflict of interest, relating to a situation where a person would use his or her position of power to create an opportunity in favor of a group member (Abdalla, Maghrabi, \& Raggad, 1998).

Nepotistic behaviors are more or less present in every culture in different forms. In the United States, belonging to a certain fraternity, society or having attended a certain university might result in favoritisms toward individuals sharing a similar background. The same can be said for British clubs, Chinese Guanxi and Brazilian Jeitinho (e.g. Chan et al., 2002; Ferreira et 
al., 2012). In Italy, nepotistic behaviors take place in the form of network recommendations for jobs, positions or business deals, political and religious affiliations contribute too. This results in the exploitation of the "world in the middle" to favor individual interests, often resulting in corruptions and crime. In the Middle East, most of the societies have the traits of tribalism, which favors nepotism according to tribe networks, religion and political affinity.

Nepotistic behavior can easily be related to both conflict creation and management. Favoritisms toward in-group members have been reported to increase the level of conflict in an organizational setting due to perceived or real differences of treatment among participants to a given organization (e.g. Druckman, 2006; Vanhoomissen and Van Overwalle, 2010). In the Middle East one of the main forms of nepotism is represented by the term "wasta". As Cunningham and Sarayrah (1993) explain, Wasta refers to situations when relationships between people are used to achieve goals through linking middle people who share common benefits, favors, interests, background, and/or characteristics. Similarly, the term pulling strings is common in the United Kingdom, and is based on gaining favors through networks, which may be either long-term connections, such as family, or short-term connections, such as acquaintances. It involves a middle person who gives a particular benefit for a certain party. This benefit can be mutual or a returned favor. According to Van de Vliert et al. (1993), a favor may be done according to the relation of tribal background and origin. The main use of Wasta back in the 1930s was for conflict resolution, after which it evolved like any cultural aspect (Cunningham and Sarayrah, 1993). Still nowadays, Wastas are used to deal with complex conflicts, particularly between tribes (Abdalla, 1996). Often portrayed as an example of corruption, Wasta is also seen by some authors as valuable for the society in giving "individuals a sense of belonging to a social entity that provides unconditional acceptance, and assistance to the novice in solving problems that are commonplace to someone more experienced. These functions are positive for the individual and for society" (Cunningham and Sarayrah, 1993, p. 191). Being, highly embedded in the society, it is expected that attitude toward nepotism is a major player in determining the conflict management styles of Jordanians. Surprisingly, no study to date has approached the relationship between attitudes toward nepotism and conflict management style preferences, and therefore the following broad research question is posed.

RQ3. Is attitude toward nepotism a predictor of conflict management styles?

\subsection{Conflict Management Styles and individual differences (e.g. demographic)}

Differences in conflict management style preferences across demographic variables have been widely revealed in research. It is generally understood that women's preferences for 
conflict management styles are distinct from men's (Ting-Toomey et al., 2001). Indeed, many studies have found that males are usually more prone than women to adopt the dominating style (Berryman-Fink and Brunner, 1987; Brewer et al., 2002; Thomas et al., 2008). These findings were later confirmed by several other studies (e.g. Croucher et al., 2011). Yet, there is less agreement in the field as to how females generally manage conflict. Some have found that females are more likely to choose the compromising style (Berryman-Fink and Brunner, 1987; Holt and DeVore, 2005), while others have found that other styles are preferred, such as accommodating (Rosenthal and Hautaluoma, 1988) and avoiding (Brewer et al., 2002). Differences in conflict management styles can be related to the diverse traits that each gender holds. Males, for instance, are found to be more assertive, more aggressive, and higher in locus of control than females. As a result, males make more use of the dominating style. Females, on the other hand, are found to be more warm, friendly, and socially sensitive. In general, both males and females tend to use conflict management styles that parallel their gender-role expectations (Wachter, 1999).

Other studies investigated inter-generational differences among different cultures, finding that there were distinct conflict management style preferences within young and old generations (e.g. Zhang, 2007). Croucher and colleagues (2011) found in their study in India that older people prefer dominating styles over compromising styles. Conversely, a study of 303 managers and future managers conducted in Singapore by McKenna and Richardson (1995) showed that older respondents preferred the compromising style. Other studies concluded that no relation exists between age and conflict management styles (e.g., Konovsky et al., 1989; Krumov et al., 1997).

There are significant differences regarding how individuals manage conflict according to their educational backgrounds (Morris et al., 1998; Ting-Toomey, 1985; Ting-Toomey et al., 2000). However, there has been no agreement so far on the effect of this variable. For example, a study of airline and journalism sectors in the U.S. found that higher levels of education were associated with the dominating conflict management style (Pinto and Ferrer Jr, 2002), yet studies conducted in India (Croucher et al., 2011) and Croatia (Vokić and Sontor, 2009) showed a decrease in preference for the dominating style associated with an increased level of education. Furthermore, individuals with lower levels of education also fail to choose the right conflict management style at the right time, as opposed to their counterparts with higher levels of education (Kurdek, 1991).

These findings from previous research show that individual differences are related to differences in conflict management styles preferences. The contradictions found among different variables seem to be explained by the fact that studies undertaken in different cultures have obtained different results. Interestingly, little research has been done in the Middle East 
on the subject, while the majority of the findings tend to come from the United States, East Asia and India (Croucher et al., 2011; Ting-Toomey et al., 2001). Given the contradictory findings and the limited research done on the Arab culture, the following research question is proposed to investigate whether or not previously demonstrated patterns apply in Jordan, and the Middle East.

RQ4. To what extent are age, gender, religion and level of education predictors of conflict management style preferences?

\section{Method}

\subsection{Participants}

Participants for a self-reported survey came to a total of 588 individuals, with diverse backgrounds in terms of education, religion, culture and geographical origin. Participants' age ranged from 18 to 73 years of age $(M=26.82, S D=9.19)$. Participants were recruited via network sampling, a data collection technique based on researchers' personal contacts and snowball sampling in order to recruit respondents from the working adult population (Croucher et al., 2011; Demerouti and Rispens, 2014; Petrou and Bakker, 2015). To include all aspects of the Jordanian society, questionnaires were distributed to students, employees, and unemployed individuals through different means. Participants were recruited by email, through announcements on online social networks and paper distribution to organizations. Participants were informed of the research purpose of the study, written consent was obtained from all participants and all responses were kept entirely anonymous. Therefore, the overall number of contacted individuals is unknown. In addition to demographic data, questionnaires contained self-assessment scales on conflict styles, religious motivation and nepotism as described below. Descriptive statistics of the sample are shown in Table 1.

Table 1 - Participants' characteristics

\begin{tabular}{|c|c|c|c|c|c|c|c|c|c|c|}
\hline \multirow[b]{2}{*}{ Items } & \multicolumn{2}{|c|}{ Gender } & \multicolumn{4}{|c|}{ Educational background } & \multicolumn{4}{|c|}{ Religious background } \\
\hline & $\mathrm{M}$ & $\mathrm{F}$ & $\begin{array}{l}\text { High } \\
\text { school }\end{array}$ & $\begin{array}{l}\text { Colleg } \\
\text { e }\end{array}$ & $\begin{array}{l}\text { Bachelo } \\
\text { r }\end{array}$ & Master & $\mathrm{PhD}$ & Muslim & Christian & Others \\
\hline No & 292 & 296 & 26 & 77 & 424 & 46 & 15 & 468 & 92 & 28 \\
\hline
\end{tabular}




\subsection{Instruments}

Questionnaires were administrated in both Arabic and English to allow respondents to participate with the language that best fit their capabilities. The established three-step process for translation was followed (Ekinci, 2015; Saunders et al., 2011) and comprehension of Arabic questions was also ensured through a panel of experts. The survey contained a total of 585 point Likert scale questions ranging from 1, being "strongly disagree", to 5, being "strongly agree". A 5-point Likert scale was adopted due to the characteristics of the observed sample and maintains consistency with previous research adopting this form of measurement scale (Dawes, 2008; Krosnick and Presser, 2010; Norman, 2010).

Conflict Management Styles (CMSs). In order to measure CMSs, Oetzel's (1998) 38-item conflict style instrument was adopted. The instrument was chosen as it has been widely validated in other cross-cultural studies (e.g. Kim et al., 2007; Komarraju et al., 2008; Oetzel et al., 2008; Vollmer and Wolf, 2015), particularly within the Middle-East (e.g., Al-Hamdan et al., 2011; Özkalp et al., 2009), and it has also been used to compare differences within the same country (e.g. Croucher et al., 2011). The results that the instrument produces allows for the understanding of preferred CMSs, such as avoiding, obliging, dominating, compromising, or integrating. The combined Cronbach's alphas for Oetzel's (1998) instrument ranged between 0.75 and 0.90 . In this study, the combined Cronbach's alphas scored similar values. Table 2 shows reliability estimates for each conflict management style.

Religious Motivation. For the assessment of an individual's religious motivation, Hoge's (1972) intrinsic religious motivation scale was used. For the purpose of this study the ten intrinsic items were used. This instrument focuses on religious activity and its motivation, and is considered particularly appropriate for the analysis of samples of diverse religious traditions (Croucher et al., 2011; King and Crowther, 2004). Table 2 shows reliability estimates for the intrinsic religious motivation variable.

Attitude toward Nepotism. In order to ascertain an individual's attitude toward nepotism, the 20 questions used in this survey were derived from Ford and McLaughlin (1985), which have already proven to be valid on previous studies about nepotism in Jordan (Hayajenh et al., 1994). Ford and McLaughlin's instrument measures attitudes of individuals - originally human resources managers - towards the impact of nepotism on their own jobs. This scale has been widely validated and adopted across different research domains (e.g., Abdalla et al., 1998; Arasli and Tumer, 2008; Kragh, 2012; Sidani and Thornberry, 2013). Table 2 shows reliability estimates for the attitude toward the nepotism variable. 
Table 2 - Means, standard deviations, correlations and Cronbach's alpha reliabilities for each instrument

\begin{tabular}{|c|c|c|c|c|c|c|c|c|}
\hline & & 1 & 2 & 3 & 4 & 5 & 6 & 7 \\
\hline 1 & Avoiding & 1.00 & & & & & & \\
\hline 2 & Obliging & $0.373^{*}$ & 1.00 & & & & & \\
\hline 3 & Dominating & $0.284 *$ & $0.121^{*}$ & 1.00 & & & & \\
\hline 4 & Compromising & $0.288^{*}$ & $0.588^{*}$ & $0.124 *$ & 1.00 & & & \\
\hline 5 & Integrating & 0.036 & $0.534 *$ & -0.025 & $0.797 *$ & 1.00 & & \\
\hline 6 & Intrinsic Religious Motivation & $0.175^{*}$ & $0.110^{*}$ & -0.079 & $0.158^{*}$ & $0.168^{*}$ & 1.00 & \\
\hline \multirow[t]{4}{*}{7} & Nepotism & $0.151 *$ & $0.125^{*}$ & $0.293 *$ & 0.006 & -0.048 & -0.050 & 1.00 \\
\hline & Mean & 3.09 & 3.63 & 3.03 & 3.91 & 4.20 & 3.77 & 2.70 \\
\hline & SD & 0.67 & 0.54 & 0.70 & 0.53 & 0.55 & 0.73 & 0.66 \\
\hline & Alpha reliability & 0.757 & 0.704 & 0.655 & 0.756 & 0.873 & 0.844 & 0.802 \\
\hline
\end{tabular}

Note: $* p<0.01, \mathrm{n}=588$

To test the research questions, multiple regression models were constructed for each conflict management style, using each conflict management style as the dependent variable, and religious motivation, nepotism and a series of control variables (age, gender, education and religious background) as independent variables. Dummy variables were created for gender, religion and education. Gender was dummy coded with "female" as the reference group, and religion was coded with "Muslim" as the reference group. In the case of education, due to the distribution of the sample responses were aggregated in two groups: those with a university degree (Bachelor's degree and above) and those without a university degree (High school and college). As a result, education was dummy coded with "university degree" as the reference group.

\section{Results}

The results of the analyses carried out with a series of multiple regression models targeting each conflict management style are reported in this section. The analysis of the means demonstrates that the preferred conflict management style in Jordan is the integrating style (M $=4.20, \mathrm{SD}=0.55)$, followed by compromising $(\mathrm{M}=3.91, \mathrm{SD}=0.53)$ and obliging $(\mathrm{M}=3.63$, $\mathrm{SD}=0.54)$

$R Q 2, R Q 3$ and $R Q 4$ asked whether intrinsic religious motivation (IRM), nepotism (NEP) and demographic variables, such as age, gender, education and religious background, have an impact on the choice of conflict management style. The multiple regression equation for the avoiding conflict management style is $R_{\text {adj }}^{2}=0.061 ; \mathrm{Y}=2.122+0.007$ (Age) +0.001 (Female) -0.062 (University) -0.095 (Muslim) $+0.171($ IRM $)+0.171$ (NEP). Model 6 was the most significant $(F=7.323, p<0.0001)$. Among all variables only age, intrinsic religious motivation 
and attitude toward nepotism were found to be significant. See Table 3 for complete regression models for the avoiding style.

Table 3 - Regression models predicting avoiding style

\begin{tabular}{lllllll}
\hline Regressor & Model 1 & Model 2 & Model 3 & Model 4 & Model 5 & Model 6 \\
\hline Intercept & 2.939 & 2.914 & 3.179 & 3.199 & 2.705 & 2.122 \\
Age & $0.006^{+}$ & $0.006^{*}$ & $0.007^{*}$ & $0.007^{*}$ & 0.005 & $0.007^{*}$ \\
Female & & 0.037 & 0.031 & 0.030 & 0.007 & 0.001 \\
University & & & $-0.076^{+}$ & $-0.076^{+}$ & $-0.078^{+}$ & -0.062 \\
Muslim & & & & -0.023 & -0.096 & -0.095 \\
IRM & & & & & $0.167^{+}$ & $0.171^{* * *}$ \\
NEP & & & & & & $0.171^{* * *}$ \\
$F$ & $3.754^{+}$ & 2.102 & $2.56^{+}$ & 1.945 & $5.258^{* * *}$ & $7.323^{* * *}$ \\
$R^{2}$ & 0.006 & 0.007 & 0.013 & 0.013 & 0.043 & 0.070 \\
$R^{2}{ }_{\text {adj }}$ & 0.005 & 0.004 & 0.008 & 0.006 & 0.035 & 0.061 \\
Notes: ${ }^{+} p<0.10 ; * p<0.05 ; * * p<0.01 ; * * *<<0.0001, \mathrm{n}=588$ & \\
\hline \hline
\end{tabular}

For the obliging conflict management style the multiple regression equation is $R_{\text {adj }}^{2}=$ $0.020 ; \mathrm{Y}=3.035-0.001($ Age $)-0.003$ (Female) +0.020 (University) -0.026 (Muslim) + $0.090($ IRM $)+0.105$ (NEP). Model 6 was the most significant $(F=2.973, p<0.0001)$. Among all variables only intrinsic religious motivation and attitude toward nepotism were found to be significant. See Table 4 for complete regression models for the obliging style.

Table 4 - Regression models predicting obliging style

\begin{tabular}{|c|c|c|c|c|c|c|}
\hline Regressor & Model 1 & Model 2 & Model 3 & Model 4 & Model 5 & Model 6 \\
\hline Intercept & 3.660 & 3.652 & 3.641 & 3.630 & 3.376 & 3.035 \\
\hline Age & -0.001 & -0.001 & -0.001 & -0.001 & -0.002 & -0.001 \\
\hline Female & & 0.012 & 0.012 & 0.012 & 0.001 & -0.003 \\
\hline University & & & 0.013 & 0.013 & 0.001 & 0.020 \\
\hline Muslim & & & & 0.012 & -0.027 & -0.026 \\
\hline IRM & & & & & $0.088 * *$ & $0.090 * *$ \\
\hline NEP & & & & & & $0.105^{* *}$ \\
\hline$F$ & 0.238 & 0.153 & 0.118 & 0.100 & 1.625 & $2.973 * *$ \\
\hline$R^{2}$ & 0.000 & 0.001 & 0.001 & 0.001 & 0.014 & 0.030 \\
\hline$R_{\text {adj }}^{2}$ & -0.001 & -0.003 & -0.005 & -0.006 & 0.005 & 0.020 \\
\hline \multicolumn{7}{|c|}{ Notes: ${ }^{+} p<0.10 ; * p<0.05 ; * * p<0.01 ; * * * p<0.0001, \mathrm{n}=588$} \\
\hline
\end{tabular}


For the dominating conflict management style the multiple regression equation is $R_{\text {adj }}^{2}=$ $0.089 ; \mathrm{Y}=2.599-0.004$ (Age) -0.068 (Female) -0.070 (University) +0.075 (Muslim) $0.059($ IRM $)+0.296$ (NEP). Model 6 was the most significant $(F=10.550, p<0.0001)$. Among all variables only attitude toward nepotism was found to be significant. See Table 5 for complete regression models for the dominating style.

Table 5 - Regression models predicting dominating style

\begin{tabular}{lllllll}
\hline Regressor & Model 1 & Model 2 & Model 3 & Model 4 & Model 5 & Model 6 \\
\hline Intercept & 3.253 & 3.296 & 3.413 & 3.373 & 3.556 & 2.599 \\
Age & $-0.008^{* *}$ & $-0.009^{* *}$ & $-0.009^{* *}$ & $-0.009^{* *}$ & $-0.008^{*}$ & -0.004 \\
Female & & -0.066 & -0.069 & -0.066 & -0.057 & -0.068 \\
University & & & $-0.131^{+}$ & $-0.131^{+}$ & $-0.123^{+}$ & -0.070 \\
Muslim & & & & 0.045 & 0.073 & 0.075 \\
IRM & & & & & -0.064 & -0.059 \\
NEP & & & & & & $0.296^{* * *}$ \\
$F$ & $6.966^{* *}$ & $4.143^{*}$ & $3.774 *$ & $2.928^{*}$ & $2.822^{*}$ & $10.550^{* * *}$ \\
$R^{2}$ & 0.012 & 0.014 & 0.019 & 0.020 & 0.024 & 0.098 \\
$R_{\text {adj }}^{2}$ & 0.010 & 0.011 & 0.014 & 0.013 & 0.015 & 0.089 \\
Notes: ${ }^{+} p<0.10 ; * p<0.05 ; * * p<0.01 ; * * *$ & $0<0.0001, \mathrm{n}=588$ & \\
\hline \hline
\end{tabular}

For the compromising conflict management style the multiple regression equation is $R_{\text {adj }}^{2}$ $=0.024 ; \mathrm{Y}=3.525-0.004($ Age $)-0.004$ (Female) +0.052 (University) -0.015 (Muslim) + 0.123 (IRM). Model 5 was the most significant $(F=3.875, p<0.01)$. Among all variables only intrinsic religious motivation and age were found to be significant. See Table 6 for complete regression models for the compromising style.

Table 6 - Regression models predicting compromising style

\begin{tabular}{lllllll}
\hline Regressor & Model 1 & Model 2 & Model 3 & Model 4 & Model 5 & Model 6 \\
\hline Intercept & 3.984 & 3.978 & 3.917 & 3.882 & 3.525 & 3.513 \\
Age & -0.003 & -0.003 & -0.003 & -0.003 & $-0.004^{+}$ & $-0.004^{+}$ \\
Female & & 0.008 & 0.010 & 0.013 & -0.004 & -0.004 \\
University & & & 0.068 & 0.068 & 0.052 & 0.052 \\
Muslim & & & & 0.040 & -0.015 & -0.015 \\
IRM & & & & & $0.124^{* * *}$ & $0.124^{* * *}$ \\
NEP & & & & & & 0.004 \\
$F$ & 1.525 & 0.780 & 0.991 & 0.874 & $3.875^{* *}$ & $3.226^{* *}$ \\
$R^{2}$ & 0.003 & 0.003 & 0.005 & 0.006 & 0.032 & 0.032 \\
$R_{\text {adj }}^{2}$ & 0.001 & -0.001 & 0.000 & -0.001 & 0.024 & 0.022 \\
Notes: ${ }^{+} p<0.10 ; * p<0.05 ; * * p<0.01 ; * * * p<0.0001, \mathrm{n}=588$ & \\
\hline \hline
\end{tabular}


For the integrating conflict management style the multiple regression equation is $R_{\text {adj }}^{2}=$ $0.029 ; \mathrm{Y}=3.696-0.002($ Age $)-0.035$ (Female) +0.116 (University) -0.040 (Muslim) + 0.134 (IRM). Model 5 was the most significant $(F=4.479, p<0.01)$. Among all variables only intrinsic religious motivation and university education were found to be significant. See Table 7 for complete regression models for the integrating style.

Table 7 - Regression models predicting integrating style

\begin{tabular}{lllllll}
\hline Regressor & Model 1 & Model 2 & Model 3 & Model 4 & Model 5 & Model 6 \\
\hline Intercept & 4.202 & 4.216 & 4.097 & 4.080 & 3.696 & 3.796 \\
Age & 0.000 & 0.000 & 0.000 & 0.000 & -0.002 & -0.002 \\
Female & & -0.022 & -0.018 & -0.017 & -0.035 & -0.034 \\
University & & & $0.134 *$ & $0.133^{*}$ & $0.116^{*}$ & $0.110+$ \\
Muslim & & & & 0.018 & -0.040 & -0.040 \\
IRM & & & & & $0.134^{* * *}$ & $0.133 * * *$ \\
NEP & & & & & & -0.031 \\
$F$ & 0.005 & 0.115 & 1.737 & 1.327 & $4.479 * *$ & $3.862 * *$ \\
$R^{2}$ & 0.000 & 0.000 & 0.009 & 0.009 & 0.037 & 0.038 \\
$R_{\text {adj }}^{2}$ & -0.002 & -0.003 & 0.004 & 0.002 & 0.029 & 0.028 \\
Notes: ${ }^{+} p<0.10 ; * p<0.05 ; * * p<0.01 ; * * * 00.0001, \mathrm{n}=588$ & \\
\hline \hline
\end{tabular}

In the next section the results of the study will be discussed and then conclusions will be drawn.

\section{Discussion}

Conflict and conflict management in Jordan has its own characteristics, due to the influences on Jordanian societies that came from colonialism, a diverse population and the more recent geopolitical events, which increased diversity and cultural tensions, due to the large influx of refugees in the country. Moreover, the Jordanian society is known for being based on tribal affiliations and rules, often leading to favoritism and nepotism based on family and tribal relations (Cunningham and Sarayrah, 1993). Accordingly, conflicts are often managed and mediated through traditions rather than standard forms of mediation. It is therefore important to understand the conflict management styles toward people in such contexts tend. However, it is also important to understand the role of cultural characteristics, such as nepotism and religious motivation, in selecting different conflict management styles. By taking those cultural elements into consideration, the results of this study expand our understanding of conflict management styles among individuals with different religious motivations and nepotistic 
attitudes in multicultural, and multi-religious, environments. The results of this study also contribute to the growing body of literature investigating conflict management in a less western environment and using employees as samples, rather than college students (e.g., Croucher, 2013; Croucher et al., 2011).

Results of this study suggested that the integrating and compromising styles of conflict management were the preferred conflict management styles in Jordan. This result is consistent with previous research linking the styles more prone to collaboration to cultures where collectivism is supposed to be among the main cultural dimensions (Adair et al., 2001; Chua and Gudykunst, 1987; Zhang, 2007). Indeed, Jordan is considered a collectivistic society, where individuals are usually more inclined toward helping others and finding common solutions to problems. Interestingly, the obliging style was the style which followed the collaborative. This result can be explained by the fact that the Jordanian society has a patriarchal structure. Therefore, people in dominant positions might tend to adopt more collaborative styles to resolve conflicts among families, while people in lower societal positions might tend to oblige when handling conflicts as a form of respect toward the others. It might be interesting for future research to investigate whether these style choices change depending on the social status of the respondents. A further explanation of the integrative style being prevalent relates to a typical characteristic of the Jordanian culture. We know from the literature that culture is an integral part of shaping an individual's perceptions, attitudes, and judgments of others (Brew and Cairns, 2004); and Jordanian culture emphasizes that individuals tend to always show the positive side of things, potentially enabling the existence of false self-perception, a concept called "Mujamaleh".

Religious motivation was found to have a significantly positive effect on all styles except for the dominating one. The highest effect was found on the avoiding style, while the smallest on obliging. These results contradict Kaushal and Kwantes (2006) and Polkinghorn and Byrne (2001), which found religiosity negatively related to the avoiding style of conflict management. However, the findings confirmed the results of Wilson and Power (2004), who found that the most religious groups preferred the use of the avoiding style. This can be explained by the fact that individuals who are intrinsically motivated toward religion will tend to avoid confrontation, adhering to the values of good will of their religion. Future studies could help in deepening the understanding of the relationship between conflict management styles and religious motivation, religiosity and religious identification. In a world that is becoming increasingly more intercultural and inter-religious, where tension between groups of different religious identity is mounting in the West as in the East, it is important to understand how religion impacts conflict management to effectively mitigate the negative effects of conflict.

It seems that individual attitudes toward nepotism tend to polarise the choices of how to handle conflict toward one of two main styles; either styles where the actor passively concede 
to the other party, or where the actor tends to be competitive and aggressive to force its will on the other party. It is interesting to note that attitude toward nepotism did not have any effect on styles that tend toward collaboration. This might be explained as people prone to nepotism either accept it passively, so they know that their fate is in the hand of someone they know, or they actively enforce it, being the agent of nepotism. If that is true, these results are explained because the individuals favouring nepotism will tend to either use it to their advantage (dominating) or will passively accept (avoiding, obliging). A better understanding of the role of attitudes toward nepotism and its predictive nature in conflict management styles may help to mitigate the negative effect of conflict by taking actions, and deploying tactics, that are more consistent with the cultural context in which conflict management actors operate.

Contradictory to previous research, it is noted that individual characteristics did not provide many significant results from the investigated sample. Only a limited effect of University education on the integrating style and a limited effect of age on avoiding and compromising were found. Similarly, it is interesting to note how religion, specifically being Muslim, has a consistent effect on the conflict management style adopted, although this result was not found to be statistically significant. Being Muslim had a negative impact on all conflict management styles, apart from the dominating style. Such results, if found significant in future studies, might support previous studies on the dominant social group. Indeed, Muslims account for the majority of the Jordanian population, therefore might prefer a dominating style when handling conflict as they may feel more secure in their social dominance (e.g., Croucher et al., 2011).

Another interesting result obtained from this research is the similarity of effects found with reference to the two cooperative styles (integrating and compromising), consistently different from the uncooperative styles (such as dominating). This result, if supported by further study could help support the emergence of a different view of conflict management styles, leading to an improved framework that evolves from the dual concern model.

\subsection{Limitations}

Due to the exploratory nature of this work and the peculiarity of the investigated constructs and contexts, there are some limitations to the study and these must be addressed. The first limitation of this study is in the use of self-reported measures. Although this practice is widely used in conflict management, communication or negotiation research (e.g., Caputo, 2013; Croucher et al., 2011; Oetzel, 1998; Ting-Toomey et al., 2001), the nature of the questions asked in the revised conflict management style instrument (Oetzel, 1998) may influence individual responses. Particularly, previous studies addressed the issues of individuals' tendencies to answer questions in a way that reflects more favorably on them (Croucher et al., 2011). Moreover, sensitive issues were addressed in this study, such as 
religion, nepotism and religious motivation, which could have increased the extent of this limitation, because individuals responded according to their self-perceptions, as opposed to how they are in reality. Nevertheless, not employing self-reported instruments would be extremely difficult due to the trade-off between accuracy of measures and sample size. Moreover, as previously addressed by similar studies, the use of established and validated selfreported instruments allows for comparisons of findings across time and geography, which balances the limitation (Cai and Fink, 2002; Croucher et al., 2011).

A secondary limitation to the study arises from the nature of the sample. Although the sample has similar characteristics with the Jordanian population, it may not be completely representative. Indeed, despite the diversity in geographical origin of respondents, the majority of data were collected from the capital Amman. This in turn may have contributed to reducing the variety of the educational and cultural backgrounds of the participants. Such limitations are unfortunately common in exploratory studies in developing countries, where data collection procedures mostly rely on the personal network of the researchers (Croucher et al., 2011); a procedure that has the advantage of making participants feel more comfortable in sharing their information. Nevertheless, this limitation can provide interesting insights for future research, which could build on these findings and investigate a more diverse sample.

\section{Conclusions}

Conflict management is an under-researched topic in Arab countries, and yet at the same time it is one of the most important issues in the current dilemmatic circumstances, and this study contributes to our understanding of how cultural and religious variables affect conflict management styles. Several studies have called for research taking a "less western" perspective on cultural differences in conflict management (e.g., Imai and Gelfand, 2010). The present study goes some way in the direction of answering this call by investigating the conflict management style preferences in Jordan, and by investigating two important variables of Middle-Eastern societies; nepotism and religious motivation. From a theoretical standpoint, building on previous studies on the importance of including religious identification into conflict management research (e.g., Croucher, 2013; Polkinghorn and Byrne, 2001), this study also shows the importance of including other cultural dynamics such as the attitude toward nepotism and religious motivation. The need arises to expand this research in both Jordan and in other Arab countries, conducting cross-cultural studies. Today more than ever it is of great theoretical and practical importance to understand the role of cultural variables, such as religion and nepotism, in relationship to conflicts and their management. 
Andrea Caputo is Reader in Entrepreneurship at the Lincoln International Business School (UK). He received his PhD in Management from the University of Rome 'Tor Vergata', in Italy. He has also been Visiting Scholar at the University of Queensland Business School and at The George Washington School of Business. His main research expertise is related to negotiation, decision-making, entrepreneurship and strategic management. He has authored a number of international publications and his work has been presented at international conferences, such as the Academy of Management and the European Academy of Management. $\mathrm{He}$ is also an active management consultant and negotiator.

\section{Reference list}

Abdalla, H.F., Maghrabi, A.S. and Raggad, B.G. (1998), “Assessing the perceptions of human resource managers toward nepotism: A cross-cultural study", International Journal of Manpower, Vol. 19 No. 8, pp. 554-570.

Abdalla, I.A. (1996), "Attitudes towards women in the Arabian Gulf region", Women in Management Review, Vol. 11 No. 1, pp. 29-39.

Adair, W.L., Okumura, T. and Brett, J.M. (2001), "Negotiation behavior when cultures collide: The United States and Japan", Journal of Applied Psychology, Vol. 86 No. 3, pp. 371385 .

Al-Hamdan, Z., Shukri, R. and Anthony, D. (2011), “Conflict management styles used by nurse managers in the Sultanate of Oman", Journal of Clinical Nursing, Vol. 20 No. 3-4, pp. $571-580$.

Allport, G.W. and Ross, J.M. (1967), "Personal religious orientation and prejudice.”, Journal of Personality and Social Psychology, Vol. 5 No. 4, p. 432.

Arasli, H., Bavik, A. and Ekiz, E.H. (2006), "The effects of nepotism on human resource management: The case of three, four and five star hotels in Northern Cyprus", International Journal of Sociology and Social Policy, Vol. 26 No. 7/8, pp. 295-308.

Arasli, H. and Tumer, M. (2008), "Nepotism, Favoritism and Cronyism: A study of their effects on job stress and job satisfaction in the banking industry of north Cyprus", Social Behavior and Personality: An International Journal, Vol. 36 No. 9, pp. 1237-1250.

Ayoko, O.B., Callan, V.J. and Härtel, C.E.J. (2003), "Workplace Conflict, Bullying, and Counterproductive Behaviors", International Journal of Organizational Analysis, Vol. 11 No. 4, pp. 283-301.

Ayoko, O.B. and Härtel, C.E.J. (2003), "The role of space as both a conflict trigger and a conflict control mechanism in culturally heterogeneous workgroups", Applied Psychology, Vol. 52 No. 3, pp. 383-412.

Ayoko, O.B., Härtel, C.E.J. and Callan, V.J. (2002), "Resolving the puzzle of productive and destructive conflict in culturally heterogeneous workgroups: A communication accommodation theory approach", International Journal of Conflict Management, Vol. 
13 No. 2, pp. 165-195.

Ayoko, O.B. and Konrad, A.M. (2012), "Leaders' transformational, conflict, and emotion management behaviors in culturally diverse workgroups", Equality, Diversity and Inclusion: An International Journal, Vol. 31 No. 8, pp. 694-724.

Baker, M. and Gorsuch, R. (1982), "Trait anxiety and intrinsic-extrinsic religiousness", Journal for the Scientific Study of Religion, Vol. 21 No. 2, pp. 119-122.

Berryman-Fink, C. and Brunner, C.C. (1987), "The effects of sex of source and target on interpersonal conflict management styles", Southern Speech Communication Journal, Vol. 53 No. 1, pp. 38-48.

Billig, M. and Tajfel, H. (1973), "Social categorization and similarity in intergroup behaviour", European Journal of Social Psychology, Vol. 3 No. 1, pp. 27-52.

Blake, R. and Mouton, J. (1964), The Managerial Grid: The Key to Leadership Excellence, Gulf Publishing Company, Houston.

Branine, M. and Analoui, F. (2006), "Human resource management in Jordan”, Managing Human Resources in the Middle East, p. 145.

Brew, F.P. and Cairns, R. (2004), "Styles of managing interpersonal workplace conflict in relation to status and face concern: A study with Anglos and Chinese", International Journal of Conflict Management, Vol. 15 No. 1, pp. 27-56.

Brewer, N., Mitchell, P. and Weber, N. (2002), “Gender role, organizational status, and conflict management styles", International Journal of Conflict Management, Vol. 13 No. 1, pp. $78-94$.

Byrne, D. (1971), The Attraction Paradigm, Academic Press, New York.

Cai, D. and Fink, E. (2002), "Conflict style differences between individualists and collectivists", Communication Monographs, Vol. 69 No. 1, pp. 67-87.

Caputo, A. (2013), “A Literature Review of Cognitive Biases in Negotiation Processes”, International Journal of Conflict Management, Vol. 24 No. 4, pp. 274-398.

Caputo, A., Mehtap, S., Pellegrini, M.M. and Al-Refai, R. (2016), "Supporting opportunities for female entrepreneurs in Jordan", International Journal of Entrepreneurship and Small Business, Vol. 27 No. 2/3, pp. 384-409.

Central Intelligence Agency. (2014), “The World Factbook 2013-14”, The World Factbook 2013-14, available at: https://www.cia.gov/library/publications/the-worldfactbook/index.html.

Chan, R.Y.K., Cheng, L.T.W. and Szeto, R.W.F. (2002), "The Dynamics of Guanxi and Ethics for Chinese Executives”, Journal of Business Ethics, Vol. 41 No. 4, pp. 327-336.

Chua, E.G. and Gudykunst, W.B. (1987), "Conflict resolution styles in low- and high-context cultures.", Communication Research Reports, Vol. 4 No. 1, pp. 32-37.

Conrad, C. (1991), "Communication in conflict: Style-strategy relationships", Communication 
Monographs, Vol. 58, pp. 135-155.

Croucher, S.M. (2011), "Muslim and Christian conflict styles in Western Europe", International Journal of Conflict Management, Vol. 22 No. 1, pp. 60-74.

Croucher, S.M. (2013), "Self-construals, conflict styles, and religious identification in India", International Journal of Conflict Management, Vol. 24 No. 4, pp. 421-436.

Croucher, S.M., Holody, K.J., Hicks, M. V, Oommen, D. and DeMaris, A. (2011), “An examination of conflict style preferences in India", International Journal of Conflict Management, Vol. 22 No. 1, pp. 10-34.

Cunningham, R.B. and Sarayrah, Y.K. (1993), Wasta: The Hidden Force in Middle Eastern Society, Praeger Publishers, Westport, USA.

Dawes, J.G. (2008), "Do data characteristics change according to the number of scale points used? An experiment using 5 point, 7 point and 10 point scales", International Journal of Market Research, Vol. 51 No. 1.

Demerouti, E. and Rispens, S. (2014), "Improving the image of student-recruited samples: A commentary”, Journal of Occupational and Organizational Psychology, Vol. 87 No. 1, pp. 34-41.

De Dreu, C.K.W. (2008), “The Structure and Management of Conflict: Fighting or Defending the Status Quo", Group Processes \& Intergroup Relations, Vol. 11 No. 3, pp. 331-353.

Druckman, D. (2006), "Group Attachments in Negotiation and Collective Action", International Negotiation, Vol. 11 No. 2, pp. 229-252.

Ekinci, Y. (2015), Designing Research Questionnaires for Business and Management Students, Sage, Thousand Oaks, CA.

El-Said, H. and McDonald, F. (2001), "Institutions and Joint Ventures in the Mid dle East and North Af rica: The Case of Jor dan", Journal of Transnational Management Development, Vol. 6 No. 1-2, pp. 65-84.

Euwema, M.C. and Van Emmerik, I.J.H. (2007), "Intercultural competencies and conglomerated conflict behaviors in intercultural conflicts", International Journal of Intercultural Relations, Vol. 31 No. 4, pp. 427-441.

Euwema, M.C., Vliert, E. Van De and Bakker, A.B. (2003), "Substantive and Relational Effectiveness of Organizational Conflict Behavior", International Journal of Conflict Management, Vol. 14 No. 2, pp. 119-139.

Ferreira, M.C., Fischer, R., Porto, J.B., Pilati, R. and Milfont, T.L. (2012), "Unraveling the mystery of Brazilian Jeitinho: A cultural exploration of social norms", Personality and Social Psychology Bulletin, Vol. 38 No. 3, pp. 331-344.

Ford, R. and McLaughlin, F. (1985), "Nepotism”, Personnel Journal, Vol. 64 No. 9, pp. 5660.

Gelfand, M.J., Higgins, M., Nishii, L.H., Raver, J.L., Dominguez, A., Toyama, M., Murakami, 
F., et al. (2002), "Culture and egocentric perceptions of fairness in conflict and negotiation", Journal of Applied Psychology, Vol. 87 No. 5, pp. 833-845.

Hall, E.T. (1976), Beyond Culture, Doubleday, Garden City, NY.

Harrison, D.A., Price, K.H. and Bell, M.P. (1998), "Beyond relational demography: Time and the effects of surface-and deep-level diversity on work group cohesion", Academy of Management Journal, Vol. 41 No. 1, pp. 96-107.

Hayajenh, A.F., Maghrabi, A.S. and Al-Dabbagh, T.H. (1994), "Research note: Assessing the effect of nepotism on human resource managers", International Journal of Manpower, Vol. 15 No. 1, pp. 60-67.

Hofstede, G. (1994), Cultures and Organisation: Intercultural Cooperation and Its Importance for Survival: Software of the Mind, Harper Collins, London, UK.

Hoge, R. (1972), “A validated intrinsic religious motivation scale”, Journal for the Scientific Study of Religion, pp. 369-376.

Hogg, M. and Abrams, D. (1988), Social Identification, Routledge, London.

Holt, J.L. and DeVore, C.J. (2005), “Culture, gender, organizational role, and styles of conflict resolution: A meta-analysis", International Journal of Intercultural Relations, Vol. 29 No. 2, pp. 165-196.

Imai, L. and Gelfand, M.J. (2010), "The Culturally Intelligent Negotiator: The Impact of Cultural Intelligence (CQ) on Negotiation Sequences and Outcomes", Organizational Behavior and Human Decision Processes, Vol. 112 No. 2, pp. 83-98.

Kaushal, R. and Kwantes, C.T. (2006), "The role of culture and personality in choice of conflict management strategy", International Journal of Intercultural Relations, Vol. 30 No. 5, pp. 579-603.

Kim, T.-Y., Wang, C., Kondo, M. and Kim, T.-H. (2007), "Conflict management styles: the differences among the Chinese, Japanese, and Koreans", International Journal of Conflict Management, Vol. 18 No. 1, pp. 23-41.

King, J.E. and Crowther, M.R. (2004), "The measurement of religiosity and spirituality: Examples and issues from psychology", Journal of Organizational Change Management, Vol. 17 No. 1, pp. 83-101.

Komarraju, M., Dollinger, S.J. and Lovell, J.L. (2008), "Individualism-collectivism in horizontal and vertical directions as predictors of conflict management styles", International Journal of Conflict Management, Vol. 19 No. 1, pp. 20-35.

Konovsky, M.A., Jaster, F. and McDonald, M.A. (1989), "Using parametric statistics to explore the construct validity of the Thomas-Kilmann conflict mode survey", Management Communication Quarterly, Vol. 3 No. 2, pp. 268-290.

Kragh, S.U. (2012), "The anthropology of nepotism Social distance and reciprocity in organizations in developing countries", International Journal of Cross Cultural 
Management, Vol. 12 No. 2, pp. 247-265.

Krosnick, J.A. and Presser, S. (2010), "Question and questionnaire design”, Handbook of Survey Research, Emerald Books, New Milford, CT, Vol. 2, pp. 263-314.

Krumov, K., Ilieva, S., Karabeliova, S. and Alexieva, L. (1997), “Conflict resolution strategies in the transition to market economy", The ANNALS of the American Academy of Political and Social Science, pp. 65-74.

Kumar, R. (2004), "Culture and emotions in intercultural negotiations: An overview", in Gelfand, M.J. and Brett, J. (Eds.), Handbook of Negotiation and Culture, Stanford University Press, Stanford, CA, pp. 95-113.

Kurdek, L.A. (1991), "Correlates of relationship satisfaction in cohabiting gay and lesbian couples: integration of contextual, investment, and problem-solving models.", Journal of Personality and Social Psychology, Vol. 61 No. 6, p. 910.

Leung, T. and Kim, M.-S. (2007), "Eight Conflict Handling Styles: Validation of Model and Instrument.”, Journal of Asian Pacific Communication, Vol. 17 No. 2, pp. 173-198.

Markus, H. and Cross, S. (1990), “The interpresonal self”, in Pervin, L.A. (Ed.), Handbook of Personality: Theory and Research, Guilford, New York.

Martin, J.P. (1998), “Christianity and Islam: Lessons from Africa”, BYU L. Rev., p. 401.

McKenna, S. and Richardson, J. (1995), "Business values, management and conflict handling: issues in contemporary Singapore", Journal of Management Development, Vol. 14 No. 4, pp. 56-70.

Morris, M.W. and Fu, H.Y. (2001), "How does culture influence conflict resolution: a dynamic constructivist analysis", Social Cognition, Vol. 19 No. 3, pp. 324-349.

Morris, M.W., Williams, K.Y., Leung, K., Larrick, R., Mendoza, M.T., Bhatnagar, D., Li, J., et al. (1998), "Conflict management style: Accounting for cross-national differences", Journal of International Business Studies, pp. 729-747.

Neyrinck, B., Lens, W., Vansteenkiste, M. and Soenens, B. (2010), “Updating Allport's and Batson's Framework of Religious Orientations: A Reevaluation from the Perspective of Self-Determination Theory and Wulff's Social Cognitive Model”, Journal for the Scientific Study of Religion, Vol. 49 No. 3, pp. 425-438.

Norman, G. (2010), "Likert scales, levels of measurement and the 'laws' of statistics", Advances in Health Sciences Education, Vol. 15 No. 5, pp. 625-632.

Oetzel, J.G. (1998), “The effects of self-construals and ethnicity on self-reported conflict styles", Communication Reports, Vol. 11 No. 2, pp. 133-144.

Oetzel, J.G., Arcos, B., Mabizela, P., Weinman, A.M., Zhang, Q., Oetzel, J.G. and TingToomey, S. (2006), "Historical, political, and spiritual factors of conflict: Understanding conflict perspectives and communication in the Muslim world, China, Colombia, and 
South Africa", in Oetzel, J.G. and Ting-Toomey, S. (Eds.), The SAGE Handbook of Conflict Communication: Integrating Theory, Research and Practice, Sage Publications, Thousand Oaks, CA, pp. 549-574.

Oetzel, J.G., Garcia, A.J. and Ting-Toomey, S. (2008), “An analysis of the relationships among face concerns and facework behaviors in perceived conflict situations: A four-culture investigation", International Journal of Conflict Management, Vol. 19 No. 4, pp. 382403.

Özkalp, E., Sungur, Z. and Ayse Özdemir, A. (2009), “Conflict management styles of Turkish managers", Journal of European Industrial Training, Vol. 33 No. 5, pp. 419-438.

Petrou, P. and Bakker, A.B. (2015), "Crafting one's leisure time in response to high job strain", Human Relations, Vol. 69 No. 2, pp. 507-529.

Pinto, E.P. and Ferrer Jr, J. (2002), "Relationship between Demographic Characteristics and Conflict Handling Styles", The Center for Latin American Issues Working Paper Series.

Polkinghorn, B. and Byrne, S. (2001), "Between war and peace: An examination of conflict management styles in four conflict zones", International Journal of Conflict Management, Vol. 12 No. 1, pp. 23-46.

Rahim, M.A. (1983), "A measure of styles of handling interpersonal conflict", Academy of Management Journal, Vol. 26 No. 2, pp. 368-376.

Rosenthal, D.B. and Hautaluoma, J. (1988), "Effects of importance of issues, gender, and power of contenders on conflict management style", The Journal of Social Psychology, Vol. 128 No. 5, pp. 699-701.

Rowland, J. (2009), "Democracy and the Tribal System in Jordan: Tribalism as a Vehicle for Social Change", Independent Study Project (ISP) Collection, No. 749, pp. 1-49, http://digitalcollections.sit.edu/isp_collection/749.

Rubin, J.Z., Pruitt, D.G. and Kim, S.H. (1994), Social Conflict: Escalation, Stalemate, and Settlement, McGraw-Hill, New York, NY.

Sadri, G. (2013), "Choosing conflict resolution by culture”, Industrial Management, Vol. 55 No. 5, pp. 10-15.

Saroglou, V. (2002), "Religion and the five factors of personality: A meta-analytic review", Personality and Individual Differences, Vol. 32 No. 1, pp. 15-25.

Saunders, M.N.K., Saunders, M., Lewis, P. and Thornhill, A. (2011), Research Methods for Business Students, 5/e, Pearson Education, London, UK.

Sidani, Y.M. and Thornberry, J. (2013), "Nepotism in the Arab world: An institutional theory perspective", Business Ethics Quarterly, Vol. 23 No. 1, pp. 69-96.

Srour, A., Sagy, S., Mana, A. and Mjally-Knani, S. (2013), "Collective narratives as indicators of examining intergroup relations: The case of Palestinian Muslims and Christians in Israel”, International Journal of Conflict Management, Vol. 24 No. 3, pp. 231-244. 
Tajfel, H. (1981), Human Groups and Social Categories: Studies in Social Psychology, Cambridge University Press, Cambridge, England.

Thomas, K.W., Fann Thomas, G. and Schaubhut, N. (2008), "Conflict styles of men and women at six organization levels", International Journal of Conflict Management, Vol. 19 No. 2, pp. 148-166.

Thomas, K.W. and Kilmann, R.H. (1978), "Comparison of four instruments measuring conflict behavior", Psychological Reports, Vol. 42 No. 3c, pp. 1139-1145.

Ting-Toomey, S. (1985), “Toward a theory of conflict and culture”, in Gudykunst, W., Stewart, P. and Ting-Toomey, S. (Eds.), Communication, Culture, and Organizational Processes, Sage Publications, Beverly Hills, CA, pp. 71-86.

Ting-toomey, S. and Kurogi, A. (1998), "Facework competence in intercultural conflict: An updated face-negotiation theory", International Journal of Intercultural Relations, Vol. 22 No. 2, pp. 187-225.

Ting-Toomey, S., Yee-Jung, K.K., Shapiro, R.B., Garcia, W., Wright, T.J. and Oetzel, J.G. (2000), "Ethnic/cultural identity salience and conflict styles in four US ethnic groups", International Journal of Intercultural Relations, Vol. 24 No. 1, pp. 47-81.

Ting-Toomey, S., Oetzel, J.G. and Yee-Jung, K. (2001), "Self-construal types and conflict management styles", Communication Reports, Vol. 14 No. 2, pp. 87-104.

Tjosvold, D. (2006), "Defining conflict and making choices about its management: Lighting the dark side of organizational life", International Journal of Conflict Management, Vol. 17, pp. 87-95.

Triandis, H.C. (2000), “Culture and Conflict.”, International Journal of Psychology.

Turner, J.C., Hogg, M., Oakes, P.J. and Reicher, S.D. (1987), Rediscovering the Social Group: A Self-Categorization Theory, Basil Blackwell, New York.

UNHCR. (2013), UNHCR Global Report 2013, Geneve, Switzerland.

UNRWA. (2013), UNRWA in Figures, As of July 2013, Jerusalem.

Vanhoomissen, T. and Van Overwalle, F. (2010), "Me or not Me as Source of Ingroup Favoritism and Outgroup Derogation: A Connectionist Perspective", Social Cognition, Vol. 28 No. 1, pp. 84-109.

Van de Vliert, E. (1993), "Paths to constructive conflict management in organizations", Munduate, L. Y Barón, M.(Comp.): Gestión de Recursos Humanos Y Calidad de Vida Laboral. Madrid: EUDEMA, pp. 13-29.

Van De Vliert, E., Euwema, M.C. and Huismans, S.E. (1995), "Managing conflict with a subordinate or a superior: Effectiveness of conglomerated behavior", Journal of Applied Psychology, Vol. 80 No. 2, p. 271.

Van de Vliert, E. and Kabanoff, B. (1990), “Toward Theory-Based Measures of Conflict 
Management.”, Academy of Management Journal, Vol. 33 No. 1, pp. 199-209.

Vokić, N.P. and Sontor, S. (2009), "Conflict management styles in Croatian enterprises-The relationship between individual characteristics and conflict handling styles", FEB Working Series (Paper No. 09-05), Faculty of Economics and Business-Zagreb.

Vollmer, A. and Wolf, P. (2015), "Adaption of conflict management styles during the encounter of cultures Findings from a Russian-West European case study", International Journal of Cross Cultural Management, Vol. 15 No. 2, pp. 151-166.

Wachter, R.M. (1999), "The effect of gender and communication mode on conflict resolution", Computers in Human Behavior, Vol. 15 No. 6, pp. 763-782.

Wilson, R. and Power, M.R. (2004), "Conflict resolution styles among Australian Christians and Muslims", Australian Journal of Communications, Vol. 31 No. 2, pp. 69-85.

Worthington Jr, E.L., Kurusu, T.A., McCollough, M.E. and Sandage, S.J. (1996), “Empirical research on religion and psychotherapeutic processes and outcomes: A 10-year review and research prospectus.", Psychological Bulletin, Vol. 119 No. 3, p. 448.

Yahiaoui, D. and Zoubir, Y.H. (2006), "Human resource management in Tunisia”, Managing Human Resources in the Middle East, Vol. 233, p. 249.

Zhang, Q. (2007), "Family Communication Patterns and Conflict Styles in Chinese ParentChild Relationships", Communication Quarterly, Vol. 55 No. 1, pp. 113-128. 